\title{
O HÁBITO FAZ O MONGE? FREQUÊNCIA E AUTOPERCEPÇÃO RELIGIOSAS NO BRASIL ${ }^{*}$
}

\author{
Nina Rosas ${ }^{1}$ \\ Jerônimo Oliveira Muniz
}

\begin{abstract}
RESUMO
Utilizando a pesquisa Valores e Religião no Brasil (PVRB), este artigo apresenta dados sobre frequência e autopercepção religiosas de católicos e evangélicos. Embora os evangélicos sejam mais envolvidos com a religião que os católicos, surpreende que ambos sejam semelhantemente devotos na reza/oração e que, entre os evangélicos, os pentecostais e os históricos apresentem porcentagens de participação religiosa quase idênticas. Simula-se a distribuição das religiões brasileiras a partir do filtro de alta frequência e também a probabilidade de filiação a partir das práticas religiosas observadas. Os resultados evidenciam diminuição do grupo de católicos e aumento do de pentecostais em proporções maiores que as do Censo de 2010, e demonstram que a probabilidade de ser católico no Brasil independe da intensidade da prática religiosa adotada.
\end{abstract}

Palavras-chave: Frequência religiosa. Autodeclaração. Evangélicos. Católicos.

* Os autores agradecem aos comentários e sugestões das professoras Cristina Maria de Castro e Ana Paula Verona, de Leonardo Souza Silveira e dos pareceristas anônimos da revista Mediações. Agradecem também ao Centro de Pesquisas Quantitativas em Ciências Sociais (CPEQS) da UFMG e ao financiamento do CNPq (processo 400629/2011-9).

1 Doutoranda em Sociologia pela Universidade Federal de Minas Gerais. Brasil. rosasnina@gmail.com

${ }^{2}$ Professor do departamento de Sociologia da Universidade Federal de Minas Gerais e diretor do Centro de Pesquisas Quantitativas em Ciências Sociais - CPEQS/UFMG. Brasil. jeronimo@fafich.ufmg.br 


\title{
DOES THE HABIT MAKE THE NUN? RELIGIOUS FREQUENCY AND SELF-PERCEPTION OF RELIGION IN BRAZIL
}

\begin{abstract}
Using the Brazilian Religion Survey (BRS), this article presents data on the frequency of religious activities and the religious self-perception of Catholics and Protestants. While Protestants are more involved with religion than Catholics, it is surprising that both are similarly devoted to prayer and that, among Protestants, Pentecostals and historical Protestants present almost identical percentages of religious participation. This article simulates the distribution of Brazilian religions based on a high-frequency filter, as well as the probability of affiliation based on observed religious practices. The results show a decrease in the number of Catholics and an increase in the number of Pentecostals in greater proportions than those of the 2010 Census and demonstrate that the probability of being Catholic in Brazil is independent of the intensity of religious practice adopted.
\end{abstract}

Keywords: Frequency of religious activities. Self-report. Protestants. Catholics.

Qja visando os benefícios após a morte ("motivação de salvação"), as satisfações trazidas pela participação em uma comunidade de fé ("motivação de utilidade"), ou a possibilidade de obter sucesso material ("pressão social") (AZZI; EHRENBERG, 1975), fato é que cerca de $90 \%$ da população mundial possui algum tipo de filiação religiosa (OLIVEIRA; CORTES; BALBINOTTO NETO, 2013). As religiões fornecem visões de mundo que formatam atitudes sociais e políticas que não podem ser atribuídas apenas à classe social, ao grau de escolaridade alcançado ou à raça (STEENSLAND et al., 2000). 0 maior ou o menor envolvimento dos indivíduos com as diversas expressões de fé tem forte relação com comportamento sexual, número de filhos, planejamento familiar, modo como a renda é empregada, grau de escolaridade almejado, envolvimento em redes sociais. Também se relaciona com inserção no mercado de trabalho, definição de papéis de gênero, satisfação pessoal etc. (ANUATTI-NETO; NARITA, 2004; IANNACCONE, 1998; LIM; PUTNAM, 2010; NOVAES, 2005; OGLAND; VERONA, 2011; PRANDI, 2008; ROSAS; CASTRO, 2014; SMITH; DENTON, 2005).

Um dos indicadores mais utilizados para se compreender o envolvimento religioso dos indivíduos é a frequência à igreja. Nos Estados Unidos, país onde sobejam dados sobre a temática, já se provou que a proporção dos que vão aos 
cultos ao menos uma vez por semana é menor do que a reportada ${ }^{3}$. É crescente 0 número de pessoas que raramente ou nunca frequentam reuniões em igrejas ou sinagogas (PEW RESEARCH CENTER, 2013a). Quase dez por cento dos que frequentam eventualmente não atribuem nenhuma causa particular a tal comportamento (PEW RESEARCH CENTER, 2013b) ${ }^{4}$. A menor frequência é típica da secularização da modernidade (BERGER, 2002; CASANOVA, 2001; HADAWAY; MARLER, 2005; ZEPEDA, 2010), também caracterizada por pluralismo religioso, "desteologização", enfraquecimento da capacidade coercitiva das congregações e surgimento do espontaneísmo (JUNGBLUT, 2012).

Também se associa a essa mesma modernidade o destacável sucesso e a grande membresia que empreendimentos religiosos têm alcançado nos últimos anos (CHANG; LIM, 2009; FRESTON, 2005, 2009). A hipótese da desregulação estatal - quanto mais livre e diversificado e menos regulado pelo Estado o mercado religioso for, maior será 0 envolvimento dos indivíduos em práticas de fé - representa um dos esforços teóricos para se compreender a vitalidade religiosa observada em certos contextos (AARTS et al., 2010; IANNACCONE; FINKE; STARK, 1997) ${ }^{5}$. O Brasil é um bom exemplo dessa vitalidade. Ainda com a maior população de católicos do mundo, apresenta expressivo aumento do número de evangélicos, que já somam 22,2\% da população, segundo o último recenseamento oficial, feito em 2010. Como tal aumento se deve sobretudo aos convertidos ao pentecostalismo ${ }^{6}$, o país vem se transformando em um dos centros mundiais

\footnotetext{
${ }^{3}$ Pesquisadores relatam que, quando o sujeito responde quantas vezes vai a um culto, a resposta mostra muito mais o que ele já foi, gostaria ou pretende ser, do que o que realmente faz (AARTES et al., 2010; IANNACCONE, 2004).

4 37\% atribuem a desacordos com os líderes religiosos ou com as crenças da igreja, $24 \%$ a prioridades pessoais e $24 \%$ a dificuldades práticas (PEW RESEARCH CENTER, 2013b).

${ }^{5}$ Seguindo essa trilha, os economistas da religião apostaram que as preferências e os gostos religiosos seriam estáveis ao longo do tempo e que os indivíduos se comportariam para maximizar os benefícios e minimizar os custos de suas opções em relação à fé. A liberdade de escolha se coadunaria com a desregulação da comercialização de bens e serviços religiosos, influenciando 0 conteúdo das commodities e a competitividade entre as firmas (igrejas), de modo que a concorrência retiraria de cena as ofertas ineficientes, fazendo com que as necessidades dos consumidores fossem atendidas (OLIVEIRA; CORTES; BALBINOTTO NETO, 2011).

${ }^{6} 0$ pentecostalismo brasileiro é complexo e heterogêneo, e foi dividido pelos sociólogos, para melhor compreensão do fenômeno, em três principais ondas: a primeira de 1910-1911, a segunda de 1950 e a terceira de 1970 (FRESTON, 1994). O número de pentecostais cresceu significativamente a partir da adesão dos indivíduos a igrejas da terceira onda, que acentuaram 0 proselitismo nas mídias eletrônicas por meio de apelos de cura e prosperidade (ALMEIDA, 2008; ANTONIAZZI, 2006; CAMPOS, 2008b; MARIANO, 1999). Embora haja diferenças temporais e teológicas que caracterizam as três ondas, já é consenso que elas se influenciam mutuamente e
} 
desta vertente de fé, com a segunda maior população de "protestantes praticantes" (FRESTON, 2005; 2009; 2010).

A intensidade do trânsito religioso dos fiéis e a emergência de novas alternativas de fé $^{7}$ se apresentam como desafio para os estudiosos do(s) fenômeno(s), sobretudo por não haver no Brasil dados quantitativos regulares e temporalmente comparáveis sobre frequência a igreja ou templos, nem sobre variações nas práticas religiosas (OLIVEIRA; CORTES; BALBINOTTO NETO, 2013). Além de entrevistas e observações de campo, os pesquisadores se valem principalmente de dados do Censo - pesquisa demográfica decenal gerada pelo Instituto Brasileiro de Geografia e Estatística (IBGE) - que permitem analisar a composição religiosa da população, considerando o tamanho e a evolução numérica dos grupos.

0 Censo coleta a autoclassificação religiosa dos sujeitos em categorias excludentes desde $1940^{8}$, tornando a autodeclaração de pertencimento a medida mais utilizada para tratar a adesão a grupos de fé. Porém, não há avanço no sentido de criar outras formas de mensuração. Embora as diferenças declaradas pelos sujeitos e posteriormente sumarizadas pelo Censo sejam relevantes para marcar incongruências eclesiológicas e históricas entre as variadas opções religiosas, as pessoas podem declarar pertencimento a religiões distintas e vivenciá-las de forma semelhante 9 . Também podem se dizer parte de uma mesma religião e terem práticas de fé bem distintas. Isso faz com que a informação coletada seja consideravelmente incompleta em termos quantitativos, e as categorias de análise decorrentes sejam por vezes inadequadas, podendo perder

que não predomina entre os pentecostais o ascetismo e 0 sectarismo do início do século (MARIANO, 2005). A literatura especializada (MARIANO, 1996, nota 2), considera como pentecostais os indivíduos que declaram estar filiados a igrejas que poderiam ser classificadas dentro de uma das três ondas. A partir de tal atestação e tendo em vista as variáveis da base de dados utilizada para este artigo, empregaremos a nomenclatura "pentecostal" de modo abrangente, fazendo referência à crença na contemporaneidade dos dons do Espírito Santo (ROLIM, 1985).

${ }^{7}$ Uma análise dos "novos movimentos religiosos" pode ser vista em Camurça (2003), Giumbelli (2002), Guerriero (2006) e Machado (2010).

8 Durante a aplicação do questionário é feita uma pergunta aberta que posteriormente é categorizada. A exceção a este procedimento foi o Censo de 1991, que apresentou opções religiosas a priori. No geral, é possível declarar pertencimento a qualquer conjunto de crenças, ideologias ou costumes (DECOL, 1999).

${ }^{9}$ Hoje em dia, além da umbanda, há também igrejas evangélicas que permitem tanto uma adesão comprometida quanto um envolvimento pouco engajado por parte do fiel. A Universal do Reino de Deus (IURD) é uma delas. 
efeitos que deveriam ser atribuídos à religião e que são erroneamente capturados por variáveis como raça, gênero e região (STEENSLAND et al., 2000).

A fim de contribuir para o debate e demonstrar até que ponto a autodeclaração é uma medida satisfatória, o presente artigo examina a filiação religiosa embasando-se no modo como as pessoas praticam sua religiosidade. Os grupos de referência utilizados são os dois numericamente mais representativos no contexto brasileiro: de um lado católicos, e de outro, evangélicos (pentecostais e não pentecostais $)^{10}$. Dados sobre os sem-religião complementam a abordagem. Lançamos mão das seguintes informações: 1) percepção do fiel quanto à própria religiosidade; 2) frequência com que se reza/ora; 3) frequência com que se vai a cultos; e 4) frequência de participação em atividades da igreja ${ }^{11}$. A partir destas informações agrupamos as pessoas segundo a "intensidade" de suas práticas e, como resultado, constatamos que caso a composição religiosa da população fosse ponderada e definida apenas para os que praticam sua religiosidade, veríamos a diminuição do grupo de católicos e 0 aumento do de pentecostais em proporções maiores que as do Censo 2010.

Embora os dados sejam de 2002, a Pesquisa Valores e Religião no Brasil (PVRB) (SCALON; GREELEY, 2005) é uma das poucas que permitem investigar a associação entre o pertencimento religioso e 0 modo de vivência da fé ${ }^{12}$. A partir

\footnotetext{
${ }^{10}$ A nomenclatura "evangélicos" não fará distinção entre "pentecostais" e "não pentecostais". Estes últimos doravante também serão chamados de "históricos", em função de evocarem uma tradição denominacional, advinda da Reforma Protestante, que se justapõe à aceitação de um ou outro dom do Espírito Santo.

${ }^{11}$ Com base na Pesquisa Valores e Religião no Brasil , o que chamamos de "filiação religiosa" ou "declaração de pertencimento" baseia-se na resposta à seguinte pergunta aberta: "Atualmente, qual a religião do Sr.(a)?” Já a "autopercepção religiosa” está pautada na pergunta : "0 Sr.(a) se considera como...", cuja resposta varia em uma escala ordinal entre 1 e 7 , sendo " $1=$ extremamente religioso" e "7= extremamente não religioso". Por fim, a "frequência religiosa" baseia-se em três perguntas: "Com que frequência o Sr.(a) vai ao culto religioso/igreja?"; "Com que frequência o Sr.(a) reza?”; e, "Além das cerimônias religiosas, com que frequência participa das atividades da igreja/culto religioso?". A autopercepção e as frequências religiosas predefinidas foram recategorizadas entre as opções "Alta", "Média", "Baixa" e "Nunca", a fim de facilitar a comparação entre elas e a visualização do grau de envolvimento dos indivíduos (ver Apêndice 1).

${ }^{12}$ Além da PVRB, o suplemento da Pesquisa Nacional por Amostra de Domicílios (PNAD), realizada pelo IBGE em 1988, e a Pesquisa Social Brasileira (PESB) de 2004, realizada pela Universidade Federal Fluminense, também coletaram informações sobre frequência, filiação e crenças religiosas. Estas pesquisas foram utilizadas por economistas para investigar a frequência da adesão religiosa segundo atributos socioeconômicos (ANUATTI-NETO; NARITA, 2004) e para "testar as premissas da Escolha Racional Religiosa aplicadas à Teoria do Consumidor" (OLIVEIRA; CORTES; BALBINOTTO NETO, 2011, p. 828).
} 
dela evidenciamos o impacto que distintas formas de classificação têm sobre a percepção de realidades estatísticas, discussão que também vem motivando trabalhos em outras áreas, como a de Sociologia da raça/ cor (BAILEY; LOVEMAN; MUNIZ, 2013; LOVEMAN; MUNIZ; BAILEY, 2012; MUNIZ, 2012). Este estudo contribui, portanto, para questionar o modo como categorias de análise são construídas; afinal, a escolha delas influencia diretamente a compreensão da composição dos grupos religiosos e da dinâmica de crescimento e diminuição dos mesmos.

0 texto está dividido em quatro partes. A primeira traça um panorama sobre algumas tentativas de classificação das expressões religiosas e discorre sobre os vários entendimentos a respeito do envolvimento dos indivíduos em grupos de fé. A segunda parte apresenta informações sobre os dados secundários utilizados e narra a metodologia. A terceira seção compara a declaração de pertencimento religioso com a prática dos fiéis, apresentando a composição dos grupos condicionada a alta ou baixa frequência religiosa. A quarta seção conclui 0 artigo.

\section{SOBRE AS CLASSIFICAÇÕES RELIGIOSAS NO BRASIL}

A exposição dos questionamentos sobre os esquemas classificatórios das religiões no Brasil pode começar a partir de uma pergunta feita por Emerson Giumbelli e reformulada por Paula Montero (2006, p. 50): "onde, quando e por quem os sistemas classificatórios são inventados e de que maneira adquirem legitimidade para serem aceitos como tais?". A resposta da autora passa por um sofisticado percurso analítico sobre a relação entre religião e esfera pública no Brasil, ressaltando que a história das religiões em nosso país é uma história de grupos que buscaram obter legitimidade se relacionando em alguma medida com a antiga religião oficial - 0 catolicismo. Manifestações de crenças e práticas não católicas, como a umbanda e o espiritismo, tiveram que lutar para que seus ritos e costumes fossem descriminalizados.

Ainda que a separação da Igreja Católica e do Estado seja oficial e suposta desde a Proclamação da República, por muitos anos o catolicismo foi hegemônico e gozou de grandes privilégios. Na época da colonização portuguesa, uma vez que ao Estado cabia o comando e a disciplina da ordem religiosa (pelo sistema do padroado), sacerdotes e missionários da Igreja Católica eram funcionários reais (CARREIR0, 2007). A inserção de outras religiões não cristãs no território nacional, como as dos escravos, por exemplo, era reprimida. Entre as alternativas de fé de matriz cristã, a vinda de protestantes europeus e norte-americanos 
chegados com motivações missionárias ocorreu principalmente após 1850. Já de 1910 em diante, o pentecostalismo se desenvolveu no país, sendo acompanhado pelo surgimento de várias opções denominacionais, como as pioneiras Assembleia de Deus e Congregação Cristã do Brasil. Naquela época, outras religiões também entraram em evidência, como o espiritismo. Mas foi só a partir de 1960 que 0 catolicismo declinou de maneira notável, algo chamado por Pierucci (2008) de tendência à "destradicionalização", que afetaria qualquer religião que tivesse detido o poder simbólico por tanto tempo.

Segundo Montero e Almeida (2000), fatores como a Guerra Fria e a descolonização da África em âmbito internacional, além do "enferrujamento da Igreja Católica com o regime militar" em âmbito local, também ocasionaram tanto uma abertura democrática e ecumênica do catolicismo, quanto o desenvolvimento de um "catolicismo dos pobres" (que diminuía a ênfase nas procissões e nos milagres dos santos e focava na conscientização política das camadas populares). Isso fez o catolicismo perder força e dar espaço a outras religiões. A visibilidade e 0 reconhecimento que alternativas de fé não católicas passaram a disputar geraram esforços dos pesquisadores para criar e adequar classificações que abarcassem os conjuntos de crenças e práticas, nem sempre novos, mas que passaram a estar em evidência.

A título de exemplo do impacto que as alterações da composição religiosa tiveram no emprego das tipologias, Ricardo Mariano (2005), se referindo ao campo evangélico, mostrou como as classificações mais utilizadas tentavam definir os pentecostalismos usando termos diversos em relação aos quais não havia consenso: "pentecostalismo autônomo", "cura divina", "pequenas seitas" etc. Mariano argumentou que o emprego de um mesmo termo por vezes fazia referência a coisas distintas, isto é, ora se levava em conta as características rituais, ora a projeção nacional das igrejas, ora a condição socioeconômica dos fiéis (MARIANO, 2005, p. 25). Posteriormente, Giumbelli (2000) inventariou os vários critérios adotados para o estabelecimento das tipologias que visam distinguir os pentecostalismos, e apontou que era considerado: o nível de centralização do governo eclesiástico, a genealogia, as ênfases teológicas, a relação com igrejas protestantes e com o ascetismo. Embora não caiba aqui retomar todo o debate proposto por esses autores, importa frisar a dificuldade no estabelecimento de critérios comuns de mensuração.

Os esforços classificatórios no Brasil demonstram a busca de reconhecimento de distintas alternativas de fé e decorrem também de alterações no cenário religioso. As categorias empregadas por grande parte das pesquisas 
quantitativas se baseiam nas tipologias daí decorrentes. Desse modo, é possível depreender que a simples declaração de pertencimento dada pelo sujeito que responde a um questionário não é um indicador suficiente do envolvimento religioso. Fica de fora da observação um elemento chave, a saber, o modo como as pessoas vivenciam a fé. Muitas religiões na contemporaneidade atraem fiéis sem necessariamente exigir dos mesmos um comprometimento moral e uma adesão formal (HERVIEU-LÉGER, 2008; POLLAK-ELTZ, 2003, p. 86-88), o que dificulta a compreensão de como crenças, cultos e ritos de fato exercem influência.

Assim é pertinente questionar como os limites da categorização se dilatam ou se contraem quando ênfase é dada à vivência religiosa ao invés de limitar-se à declaração de pertencimento. Faz sentido perguntar até que ponto a filiação a um grupo tal informa sobre a intensidade com que se vive a fé. De fato, a autoclassificação de pertencimento só pode explicar a diferença na vivência da religião se pressupusermos que as instituições religiosas ainda conseguem reproduzir, ao menos na maior parte dos crentes, as diferenças estabelecidas pelos critérios de classificação já elaborados.

Para compreender o cenário brasileiro - que é de diminuição do catolicismo, retração da umbanda e do protestantismo advindo de imigrantes (como o luteranismo) e expressivo aumento do número dos que se declaram sem religião (PIERUCCI, 2004) - o exercício que será apresentado incluirá a medição da intensidade religiosa, ou seja, o modo como os indivíduos exercitam a fé. Duas perguntas norteiam a pesquisa: 1) Quais grupos são mais religiosos, católicos ou evangélicos? Há diferenças significativas de engajamento entre eles? 2) Como a distribuição de católicos e evangélicos no Brasil é alterada quando se adota como critério, além da declaração de pertença, a intensidade das práticas de fé?

\section{DADOS E METODOLOGIA}

Nossa análise se vale de dados secundários provenientes da Pesquisa Valores e Religião no Brasil, coordenada pelo antigo IUPERJ entre os dias 21 de março e 04 de abril de 2002 (SCALON; GREELEY, 2005) ${ }^{13}$. A pesquisa utiliza uma amostragem por cotas baseada na distribuição geográfica por sexo, idade, escolaridade e renda domiciliar populacional observada no Censo Demográfico de

\footnotetext{
${ }^{13}$ Ogland e Hinojosa (2012) utilizaram a PVRB para estudar como a religião influencia julgamentos morais e formação de uniões maritais. 0 banco de dados está disponível no site do Consórcio de Informações Sociais (CIS): http://www.nadd.prp.usp.br/cis/DetalheBancoDados.aspx?cod=B52, onde se encontram também detalhes sobre o desenho amostral e a metodologia.
} 
2000. A composição religiosa é próxima a deste Censo, que apresentou $73,8 \%$ de católicos, 10,4\% de pentecostais, 4,2\% de protestantes históricos e 7,3\% de sem religião. Na PVRB, o grupo dos católicos representa $74 \%$ da amostra, seguido pelo de evangélicos, pentecostais (17\%) e não pentecostais (3\%). Aproximadamente $6 \%$ se declara "sem religião"14.

0 questionário engloba questões referentes à filiação religiosa, valores, crenças, autopercepção da religiosidade e frequências dos envolvidos em reza/oração e em cultos e atividades da igreja. A pesquisa possui 2.000 observações para homens e mulheres entre 18 e 87 anos, residentes em áreas urbanas e rurais de 195 municípios brasileiros de 24 estados e o Distrito Federal. Após a exclusão dos valores faltantes, a amostra reduz-se para 1.483 observações.

Três abordagens analíticas compõem a metodologia do artigo. A primeira compara as frequências religiosas entre as quatro categorias de pertencimento. Tal estratégia evidencia quais os grupos religiosos se aproximam ou se distanciam tendo em vista o modo como os fiéis vivenciam suas práticas.

Além disso, o grau de consistência entre a autopercepção religiosa e a religiosidade vivenciada é mostrado em uma matriz de concordância que permite, em alguma medida, validar a autopercepção a partir das frequências declaradas (atividades da igreja, culto e reza/oração). A matriz de concordância elucida se 0 modo como o fiel percebe sua religiosidade é compativel com a intensidade das práticas declaradas.

A segunda abordagem analítica consiste em descrever como seria a composição religiosa amostral caso considerássemos apenas as pessoas que possuem alta frequência em práticas religiosas específicas. Especula-se que no Brasil haja uma parcela considerável de "católicos não praticantes", isto é, que se incluem nesta categoria por força da tradição e não por prática.

Ao excluirmos da composição religiosa aqueles que nunca rezaram e nem se envolveram com cultos e atividades de suas igrejas, esperamos ter um retrato mais fidedigno da distribuição religiosa brasileira. Almejamos verificar como católicos e evangélicos "praticantes" estão representados na população, simulando assim um cenário alternativo à distribuição relativa oficial retratada por censos demográficos e surveys, que, via de regra, não ponderam as afiliações autodeclaradas pelas práticas religiosas implicadas.

\footnotetext{
${ }^{14}$ As demais crenças e os casos sem resposta (4,25\%) não foram incluídos na amostra analítica.
} 
A terceira estratégia adotada consiste em estimar as probabilidades latentes de ser católico, evangélico, ou sem religião a partir das frequências religiosas declaradas, controlando-se pelas diferenças de composição da amostra, segundo idade, sexo, status marital, região e religião dos pais das pessoas entrevistadas ${ }^{15}$. As probabilidades estimadas utilizam modelos logísticos multinomiais que, além de mensurarem a associação existente entre 0 evento de interesse e as variáveis relevantes, também permitem a construção de cenários contrafactuais que "padronizam" a análise comparativa. A "padronização" consiste em assumir que os atributos individuais permanecem os mesmos, enquanto aqueles cuja influência se deseja avaliar variam conforme o interesse do pesquisador. Cenários contrafactuais permitem perguntar, por exemplo, qual seria a probabilidade de ser classificado como católico ou evangélico assumindo que existem diferenças individuais apenas quanto à intensidade da frequência a cultos e atividades da igreja.

\section{RESULTADOS}

Os dados sobre a percepção do fiel quanto à própria religiosidade (utilizados como uma espécie de controle subjetivo da filiação) corroboram a imagem de um Brasil religioso. Mais de $30 \%$ da população amostrada se considera muito religiosa; proporção elevada sobretudo entre os pentecostais, uma vez que 54,37\% assim se considera (ver Gráfico 1 e Apêndice 2). 0 Gráfico 1 também revela que não há contradição entre não ter religião e possuir alguma religiosidade, já que mais de $76 \%$ dos que se classificam como sem religião se consideram envolvidos com a fé (alto e médio envolvimento) no grupo de "Autopercepção da religiosidade".

\footnotetext{
${ }^{15}$ Oliveira, Cortes e Balbinotto Neto (2013) utilizaram estratégia similar para estudar a associação entre atributos pessoais e frequência religiosa, utilizando dados da Pesquisa Social Brasileira (PESB) de 2004. A partir da estimação de modelos logísticos ordinais, e tendo como marco teórico o modelo de Azzi e Ehrenberg (1975), os autores concluíram que mulheres e pessoas mais velhas são mais propensas a frequentarem serviços religiosos. Já a renda teve correlação negativa com a frequência religiosa.
} 
Gráfico 1 - Composição de grupos religiosos específicos segundo a autopercepção do fiel e envolvimento em práticas religiosas

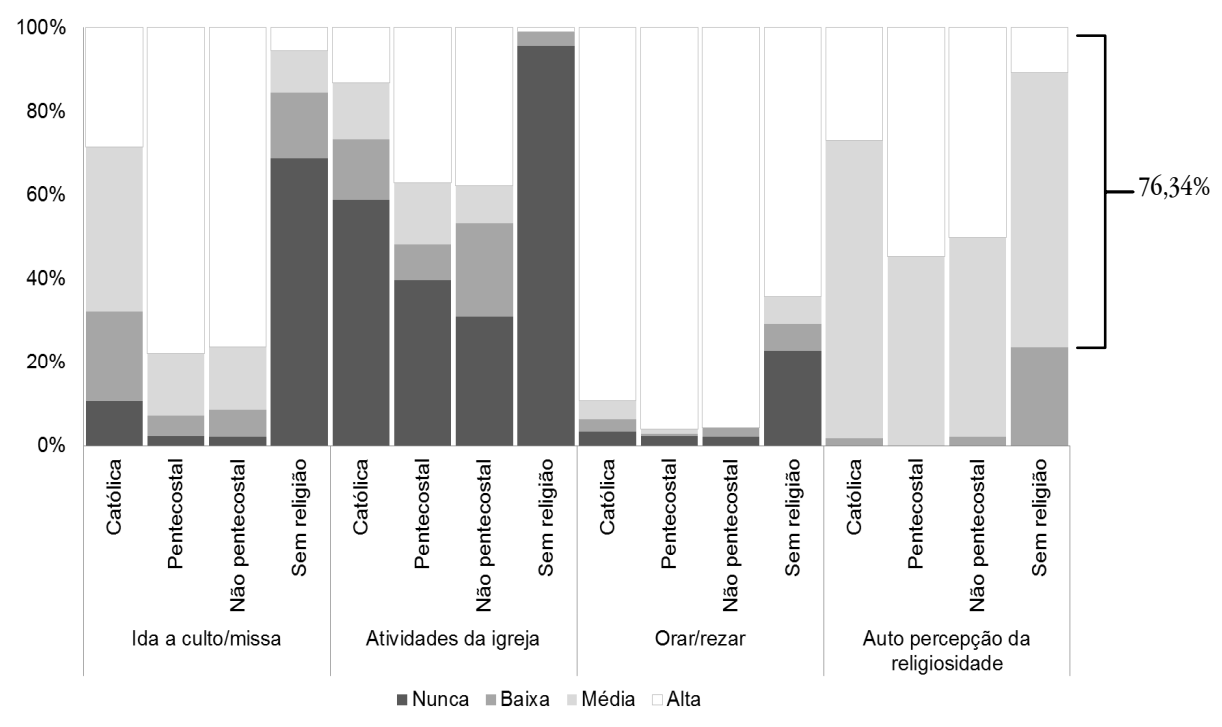

Fonte: Elaboração dos autores a partir dos dados da PVRB (CIS), 2002 (Anexo 2).

A análise das variáveis que refletem o grau de envolvimento dos entrevistados em três distintas frequências religiosas (assistir a missas/ir a cultos, participar de atividades da igreja e rezar/orar) revela que os católicos, mesmo pertencendo ao credo religioso de maior representatividade na pesquisa, são os menos engajados em atividades religiosas, como já bem mostra a autopercepção dos mesmos sobre seu envolvimento. Pouco mais de um quarto deles (28,5\%) vai à missa com frequência elevada, e somente $12,7 \%$ têm alto envolvimento em atividades da igreja (Gráfico 1). Como base nessa mensuração de engajamento, é possível dizer que a maioria dos católicos pode ser considerada "nominal", isto é, são aqueles indivíduos que vão à igreja apenas quando frequentam enterros, batismos, casamentos e alguns eventos (ALMEIDA; MONTER0, 2001).

Já os evangélicos, pentecostais e não pentecostais, apresentam percentuais superiores de participação em cultos se comparados aos católicos - 77,8\% e $76,1 \%$ respectivamente, corroborando o que tem sido defendido pelas pesquisas de religião (ALMEIDA, 2008; ALMEIDA; MONTERO, 2001; CAMPOS, 2008b; FRESTON, 1994, 2010; MARIANO, 1999; MONTERO; ALMEIDA, 2000; PIERUCCI, 2004, 2006; SANCHIS, 1997). 0 engajamento dos evangélicos em atividades da 
igreja também é elevado, sendo quase três vezes maior (37\%) que o dos católicos. o que é digno de ser negritado é que os não pentecostais se assemelham aos pentecostais quanto à autopercepção religiosa e a frequência em cultos e atividades eclesiásticas; dado que não se vê na literatura especializada.

A vertente pentecostal de desenvolvimento mais recente (0 neopentecostalismo), que fez com que tal grupo se tornasse numericamente expressivo e atingisse notável visibilidade, se estruturou de modo empresarial, passando a usar a TV e o rádio para fins proselitistas como nunca antes evangélicos haviam feito no país. Pregou prosperidade e sucesso e arregimentou uma multidão de seguidores, que passou a frequentar a igreja mais de uma vez por semana (alguns, mais de uma vez ao dia) (CAMPOS, 2008a; FRESTON, 1999, 2010; LIMA, 2010; MACHADO, 2006; MAFRA, 2001; MARIANO, 1999, 2003; MESQUITA, 2007; ORO; CORTEN; DOZON, 2003; ROSAS, 2012, 2013). Se considerarmos que isso vale para o grupo pentecostal como um todo, poderíamos imaginar encontrar menor frequência religiosa entre os protestantes históricos. Mas a partir dos dados apresentados vê-se que históricos e pentecostais se assemelham em sua religiosidade. Conjectura-se que isso é devido à renovação do protestantismo, uma vez que parte deste seguiu a tendência pentecostal/neopentecostal. Mas não se pode afirmar com certeza a razão para tal semelhança.

Quanto ao ato de rezar/orar, observa-se que todos os crentes oram muito: evangélicos pentecostais $(95,6 \%)$, não pentecostais (95,7\%), e católicos, que, mesmo um pouco menos devotos na reza, apresentam uma proporção também alta (88,9\%). Em todas as religiões analisadas é expressiva a quantidade de fiéis que declararam a manutenção de uma religiosidade, bem dizer, privatizada.

\section{Retrato da composição religiosa a partir da prática da fé}

Tendo em mente esse quadro a respeito da religiosidade dos brasileiros, é possível perguntar se o cenário da filiação religiosa sofreria alterações significativas em sua composição se considerássemos a mensuração a partir de critérios de frequência. Para responder a esta pergunta, buscamos compreender qual seria a composição religiosa no Brasil caso nos embasássemos apenas na filiação 
autodeclarada daqueles que possuem frequência alta para a ida a cultos/missa, participação em atividades da igreja e reza/oração ${ }^{16}$.

Gráfico 2 - Filiação religiosa dos que possuem alta participação em práticas religiosas.
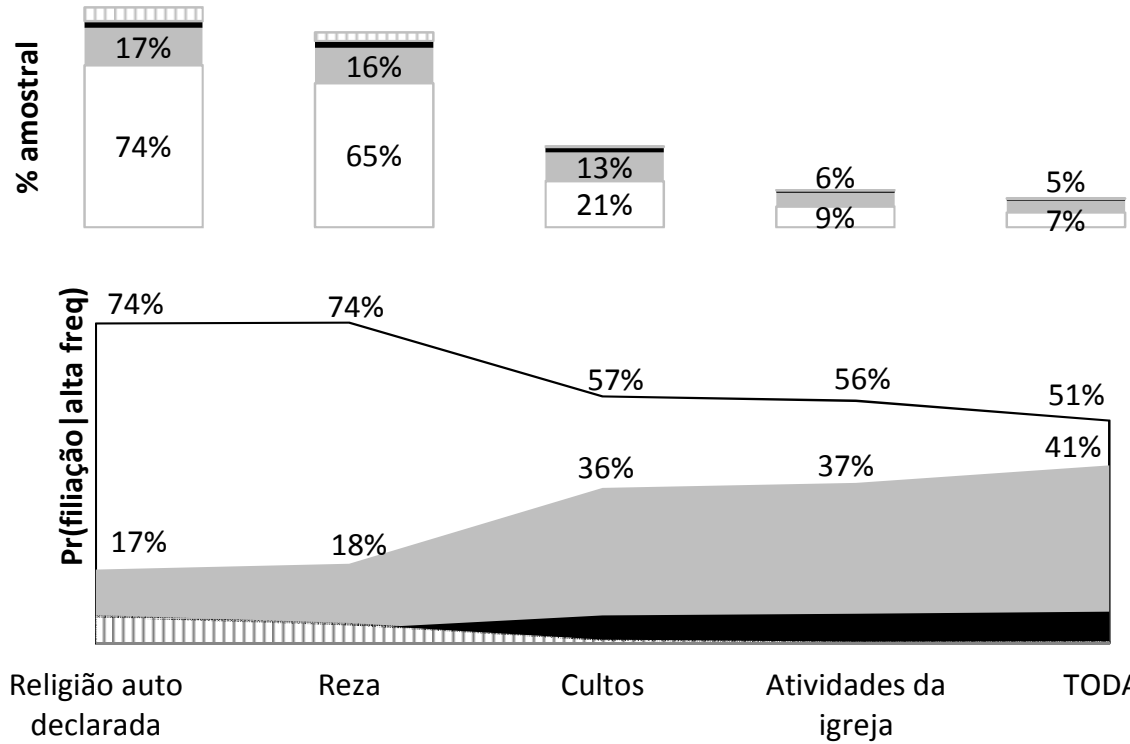

$$
\begin{aligned}
& \text { Religião auto } \\
& \text { declarada }
\end{aligned}
$$

$\square$ Católica $\square$ Pentecostal
Reza
Cultos

Atividades da

igreja
TODAS

$18 \%$

Fonte: Elaboração dos autores a partir dos dados da PVRB (CIS), 2002.

Levando em conta os que possuem alta frequência a cultos/missa e alta participação em atividades da igreja, observamos que 0 catolicismo mostra uma acentuada queda na representatividade de fiéis. Se antes autodeclarados católicos correspondiam a $74 \%$ dos brasileiros, por esse filtro, passam a representar $57 \%$. Já os evangélicos pentecostais são os que têm o maior crescimento (passam de $17 \%$ para $37 \%$ de participação na composição religiosa do país). Os dados do

\footnotetext{
${ }^{16}$ Os dados não nos permitem levar em conta fatores como: exposição a redes sociais, diferenças de normas e ensinamentos, sanções, aprendizado de técnicas etc., que também exercem influência na composição religiosa nacional.
} 
Censo 2010, por exemplo, mostraram 64,6\% de católicos e 22,2\% de evangélicos, proporções estas diferentes das do Censo 2000, mas menos acentuadas que as das simulações feitas aqui.

Quando fazemos o mesmo exercício para o ato de rezar/orar, contudo, percebemos a manutenção dos resultados obtidos apenas por meio do registro de filiação. Como o ato de rezar/orar ocupa uma posição de destaque independente do grupo, interpretamos essa expressão de religiosidade como um componente arraigado à cultura brasileira, um modo privatizado de vivenciar as crenças e os valores de uma fé; portanto, um critério que não pode ser usado para diferenciar o envolvimento dos fiéis.

A autopercepção da religiosidade também não pode ser utilizada como critério de diferenciação entre fiéis por ser incompatível com a intensidade religiosa de fato vivenciada. Isso se torna evidente ao examinarmos a Tabela 1, que apresenta percentuais de concordância para a alta (acima da diagonal principal) e para a baixa (abaixo da diagonal) intensidade religiosa. Pela Tabela 1 nota-se, por exemplo, que somente $29,4 \%$ da amostra têm alta frequência de reza/oração e se percebe como muito religiosa. Esse percentual é bem menor que o de pessoas com alta intensidade de reza/oração. Em todas as religiões consideradas, pelo menos $88 \%$ dos fiéis tem alta frequência de reza ou oração (ver Anexo 2). A maior concordância entre religiosidades percebida e vivenciada ocorre entre os que possuem alta frequência tanto em ida a cultos/missa, quanto em reza/oração (35,7\%). A menor concordância ocorre entre pessoas com baixo envolvimento em atividades da igreja e baixa religiosidade autopercebida. Apenas $0,27 \%$ das 1483 pessoas entrevistadas se consideram pouco religiosas e possuem baixa participação em atividades da igreja. Em todos os cruzamentos há uma clara dissonância entre percepção e vivência, o que sugere cautela na utilização da informação subjetiva sobre intensidade religiosa para a realização de análises empíricas. 
Tabela 1 - Concordância percentual entre religiosidades autopercebidas e vivenciadas

\begin{tabular}{|c|c|c|c|}
\hline Culto & 13,35 & 35,67 & 19,96 \\
\hline 3,64 & Igreja & 16,39 & 10,79 \\
\hline 1,62 & 0,61 & Reza & 29,4 \\
\hline 0,34 & 0,27 & 0,4 & $\begin{array}{l}\text { Intens. relig. } \\
\text { percebida }\end{array}$ \\
\hline
\end{tabular}

Nota: Os valores da tabela têm como denominador comum o tamanho de amostra $(n=$ 1483) e referem-se a cruzamentos distintos entre a intensidade religiosa percebida e a intensidade de atividades vivenciadas. Por isso, os percentuais apresentados na Tabela 1 não devem ser somados, e por isso não fecham em 100\%. A concordância sobre a categoria "alta" encontra-se acima da diagonal e a concordância sobre a categoria "baixa" encontra-se abaixo da diagonal principal da matriz. A estatística de qui-quadrado utilizada para testar a hipótese nula de independência foi significativa ao nível de $\alpha=5 \%$ em todas as tabulações cruzadas entre "religiosidade autopercebida" e "frequências de práticas religiosas", indicando assim a presença de associação estatística entre estas duas variáveis.

Fonte: Elaboração dos autores a partir dos dados da PVRB (CIS), 2002.

Em suma, a declaração de pertencimento do entrevistado, a medida de autopercepção religiosa e 0 ato de orar/rezar não refletem 0 mesmo grau de envolvimento retratado pela frequência a cultos/missa e participação em atividades da igreja. Se somente os religiosos mais fervorosos fossem considerados na composição - 13\% da amostra apresenta alta frequência em todas as práticas religiosas - 0 percentual de pentecostais seria igual a $41 \%$, enquanto 0 de católicos, $51 \%$.

\section{Probabilidades de pertencimento}

Haveria então alguma associação entre a prática religiosa e a probabilidade de se autodenominar católico, evangélico ou sem religião? Se conhecêssemos a natureza e a intensidade das práticas religiosas de alguém poderíamos inferir a qual religião este alguém pertence? Para responder a estas perguntas, calculamos as probabilidades preditas de ser católico, evangélico ou sem religião segundo 0 
tipo e a intensidade da prática da fé ${ }^{17}$. Estas probabilidades são calculadas simulando-se perfis individuais comparáveis de pessoas com alta ou baixa frequência religiosa. Por um lado, o Gráfico 3 mostra que indivíduos que possuem alta frequência a cultos, atividades da igreja e reza/oração têm elevadas probabilidades de serem evangélicos (87\%) e probabilidades quase nulas de serem sem religião $(0,6 \%)$. Por outro lado, 0 Gráfico 3 mostra que a probabilidade de ser católico independe da frequência a práticas eclesiásticas. Em média, a filiação ao catolicismo não está atrelada a práticas religiosas, já que tanto os muito religiosos quanto os que nunca praticaram uma religião possuem as mesmas probabilidades de serem católicos (@12\%).

\footnotetext{
${ }^{17}$ Para tornar a apresentação e a discussão dos resultados mais didática, as probabilidades de classificação entre católicos, evangélicos e sem religião são preditas utilizando-se a abordagem sugerida por King, Tomz e Wittenberg (2000), que utilizam simulações Monte Carlo para construir intervalos de confiança estatística. Para obtermos estimativas comparáveis, as características individuais foram fixadas e variaram-se apenas as frequências de reza/oração e presença em cultos e atividades da igreja. Idade, sexo, estado marital e as variáveis indicadoras de residência nas regiões norte, nordeste ou centro-oeste foram excluídas do modelo por não estarem estatisticamente associadas à filiação religiosa autodeclarada. As categorias "pentecostal" e "não pentecostal" foram agrupadas em uma única, denominada "evangélicos". Isso se deu por causa da similaridade estatística entre seus coeficientes. Um dos "tipos ideais" adotado possui as seguintes características: nunca rezou, nunca foi a cultos e nem participou de atividades da igreja, mora na região sudeste e possui pai católico e mãe não católica. Ao contrário da estimativa pontual comumente apresentada na saída da regressão, na simulação Monte Carlo os valores preditos são extraídos de uma distribuição de coeficientes (ex.: betas) calculados a partir de 1000 simulações bootstraps. Os coeficientes da estimativa do modelo multinomial encontram-se no Apêndice 3.
} 
Gráfico 3 - Probabilidades estimadas de filiação religiosa condicionadas à frequência de oração e de participação em atividades eclesiásticas

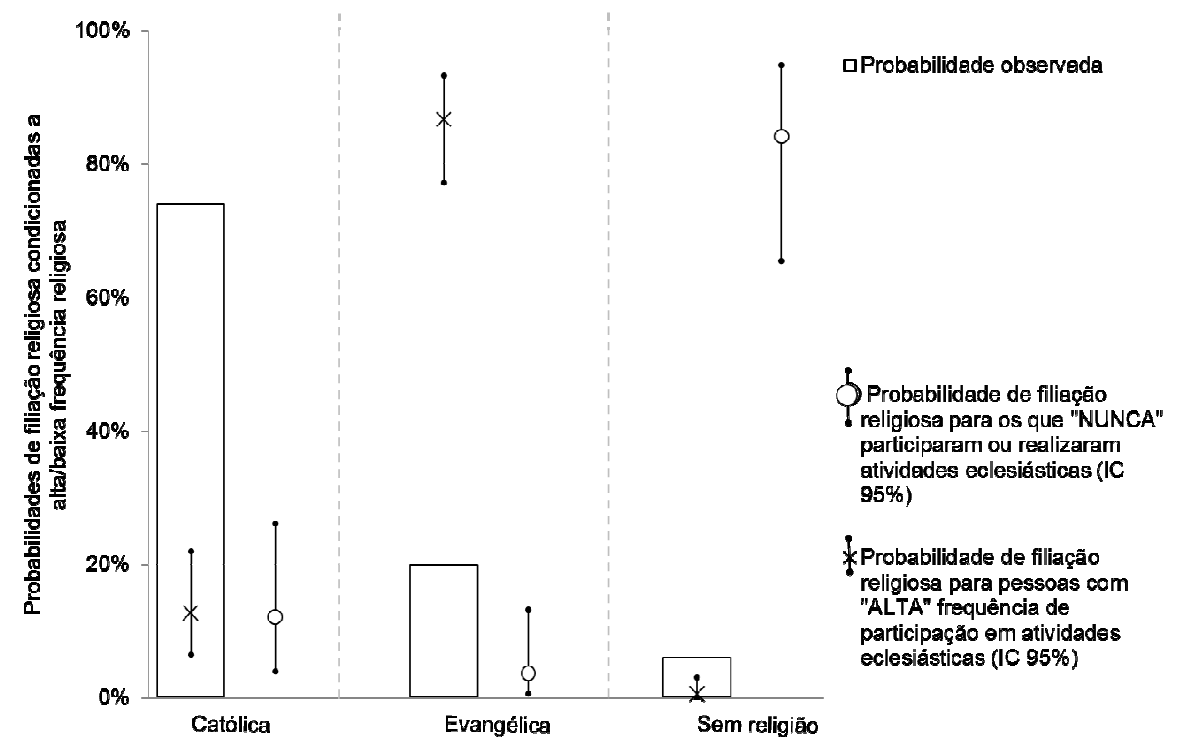

Nota: Probabilidades observadas correspondem ao percentual amostral pertencente a cada credo religioso. As probabilidades estimadas baseiam-se em "tipos ideais" definidos na nota de rodapé 15 . Todas as predições foram feitas utilizando-se intervalos de confiança estatística de 95\%.

Fonte: Elaboração dos autores a partir dos dados da PVRB (CIS), 2002.

Apesar de 74\% da amostra da PVRB ser católica, a probabilidade pontual de um "tipo ideal" (residente na região sudeste cujo pai é católico e a mãe não) se autodenominar católico é de $12 \%$, tanto para os praticantes quanto para os que nunca rezaram e nem participaram de missas e atividades da igreja. Esses resultados demonstram que a probabilidade de pertencimento ao catolicismo não está vinculada ao envolvimento dos indivíduos em atividades religiosas e elucida 0 entrelaçamento entre catolicismo e identidade nacional, na qual ainda prevalece 0 status quo da autodenominação católica, influenciada mais por tradição do que por prática.

\section{CONSIDERAÇÕES FINAIS}

A descrição estatística a que nos propusemos, dialogando com a perda da hegemonia do catolicismo, com o crescimento do pentecostalismo e com a 
redefinição do engajamento dos fiéis de modo geral, mostra um Brasil não menos religioso, mas certamente menos católico e mais evangélico do que se supõe. Por um lado, se no ano 2000 cerca de três quartos da população (73\%) era católica, e em 2010, este número chegou a 64,6\% segundo a declaração das pertenças religiosas, por outro lado, quando filtramos o percentual da PVRB pelo envolvimento dos fiéis a partir da ida a cultos/missa e participação em atividades da igreja, os católicos passam a representar pouco mais da metade da população (57\%). Este resultado corrobora a hipótese de "destradicionalização" proposta por Pierucci (2008), segundo a qual a perda de fiéis na modernidade ocorreria sobretudo nas religiões mais tradicionais. As informações levantadas mostram ainda que, caso a composição dos grupos religiosos fosse pautada pela alta intensidade da participação e prática religiosa, observaríamos uma queda maior do catolicismo do que mostram pesquisas baseadas apenas na autofiliação.

Ao simular qual seria a composição religiosa a partir daqueles que possuem alta frequência em todas as atividades eclesiásticas, viu-se que 0 percentual de pentecostais subiu para $41 \%$, número maior que os registrados pelos Censos Demográficos de $2000(15,4 \%)$ e de 2010 (22,2\%). Este artigo reforça também que evangélicos são de fato mais envolvidos com sua religião do que os católicos, embora pentecostais e não pentecostais tenham percentuais praticamente idênticos para a ida a cultos e envolvimento em atividades da igreja. Quanto à reza/oração, ainda que os católicos sejam menos dedicados a essa prática se comparados aos evangélicos, os números mostram que 0 desenvolvimento de uma religiosidade privatizada perpassa todos os credos cristãos no Brasil, e quiçá faça parte de algo compartilhado por outras formas de experimentação do sagrado que tenham identidade nacional.

Nossa análise evidencia também a fraqueza do vínculo entre religiosidade e filiação católica. A partir de modelos estatísticos contra factuais demonstramos que a probabilidade de se autodenominar católico é a mesma para praticantes e não praticantes religiosos. Já a chance de ser evangélico é mais de oito vezes a de ser católico quando a frequência a cultos é alta (ver Apêndice 3).

Em suma, ao longo da narrativa, mostramos que a realidade religiosa observada depende de como os dados são construídos e percebidos. De um lado, isso elucida as mudanças que aparecem em função de alterações nas próprias religiões/religiosidades ao longo do tempo. De outro, acentua como um mesmo cenário religioso pode ser representado de maneira distinta se alterarmos o modo de mensuração empregado. Estamos cientes de que cobrimos apenas uma das possibilidades de compreensão das pertenças religiosas no Brasil. Outras formas 
de análise do fenômeno podem levar em conta crenças, envolvimento em atividades diversas (como trabalhos sociais e redes de apoio), relação com a ciência e outros. No entanto, num tempo em que se produzem e se descartam tipologias e classificações no mesmo passo em que os religiosos transitam em múltiplas opções de pertencimento (HERVIEU-LÉGER, 2008), a intensidade da participação ocupa e deve ocupar um lugar central nas análises acadêmicas, pois pode contribuir substantivamente para pensar a elaboração da variável religião em pesquisas futuras, alterando o panorama traçado como consequência.

\section{REFERÊNCIAS}

AARTS, Olav et al. Does Duration of Deregulated Religious Markets Affect Church Attendance? Evidence from 26 Religious Markets in Europe and North America Between 1981 and 2006. Journal for the Scientific Study of Religion, Storrs, v. 49, n. 4, p. 657-672, 2010.

AGRESTI, Alan; FINLAY, Barbara. Métodos estatísticos para as ciências sociais. 4. ed. Porto Alegre: Penso, 2012.

ALMEIDA, Ronaldo de. Os pentecostais serão maioria no Brasil? REVER - Revista de Estudos da Religião, São Paulo, v. 4, p. 48-58, dez. 2008.

ALMEIDA, Ronaldo de; MONTERO, Paulo. Trânsito religioso no Brasil. São Paulo em Perspectiva, São Paulo, v. 15, n. 3, p. 92-101, 2001.

ANTONIAZZI, Alberto. Porque o panorama religioso no Brasil mudou tanto? São Paulo: Paulus, 2006.

ANUATTI-NETO, Francisco; NARITA, Renata Del Tedesco. A influência da opção religiosa na acumulação de capital humano: um estudo exploratório. Estudos Econômicos, São Paulo, v. 34, n. 3, p. 453-486, 2004.

AZZI, Corry; EHRENBERG, Ronald G. Household allocation of time and church attendance. Journal of Political Economy, Chicago, v. 83, n. 1, p. 27-56, 1975.

BAILEY, Stanley; LOVEMAN, Mara; MUNIZ, Jeronimo 0. Measures of "race" and the analysis of racial inequality in Brazil. Social Science Research, New York, v. 42, n. 1, p. 106-119, 2013.

BERGER, Peter. Introduction: the cultural dynamics of globalization. In: BERGER, Peter; HUNTINGTON, Samuel P. (Ed.). Many globalizations: cultural diversity in the contemporary world. New York: Oxford University Press, 2002. p. 1-16. 
CAMPOS, Leonildo Silveira. Evangélicos e mídia no Brasil: uma história de acertos e desacertos. REVER - Revista de Estudos da Religião, São Paulo, v. 8, p. 1-26, set. 2008a.

CAMPOS, Leonildo Silveira. Os mapas, atores e números da diversidade religiosa cristã brasileira entre 1940 e 2007. REVER - Revista de Estudos da Religião, São Paulo, v. 8, p. 9-47, dez. 2008b.

CAMURÇA, Marcelo Ayres. Secularização e reencantamento: a emergência dos novos movimentos religiosos. BIB- Revista Brasileira de Informação Bibliográfica, São Paulo, n. 56, p. 55-70, 2003.

CARREIR0, Gamaliel da Silva. Análise socio-desenvolvimental do crescimento evangélico no Brasil. 2007. Tese (Doutorado em Sociologia) - Universidade de Brasília - UNB, Brasília, 2007.

CASANOVA, Jose. Religion, the new millenium, and globalization. Sociology of Religion, Washington, v. 62, n. 4, p. 415-441, 2001.

CHANG, P. Y.; LIM, D. J. Renegotianting the Sacred-Secular Binary: IX Saves and Contemporary Christian Music. Review of Religious Research, Washington, v. 50, n. 4, p. 392-412, 2009.

DECOL, Rene D. Mudança religiosa no Brasil: uma visão demográfica. Revista Brasileira de Estudos de População, Rio de Janeiro, v. 16, n. 1/2, p. 121-137, 1999.

FRESTON, Paul. Breve história do pentecostalismo brasileiro. In: ANTONIAZZI, Alberto (Ed.). Nem anjos nem demônios: interpretações sociológicas do pentecostalismo. Petrópolis: Vozes, 1994. p.67-162.

FRESTON, Paul. "Neo-Pentecostalism" in Brazil: problems of definition and the struggle of hegemony. Archives de Sciences Sociales des Religions, Paris, v. 105, p. 145-162, 1999.

FRESTON, Paul. The Universal church of the kingdom of god: a Brazilian church finds success in Southern Africa. Journal of Religion in Africa, Leiden, Holanda v. 35, n. 1, p. 33-65, 2005.

FRESTON, Paul. Latin America: the 'Other Christendom'. In: BEYER, Peter; BEAMAN, Lori (Ed.). Religion, globalization and culture. Leiden: Brill, 2009. p. 571-593. 
FRESTON, Paul. As duas transições futuras: católicos, protestantes e sociedade na América Latina. Ciencias Sociales y Religión/Ciências Sociais e Religião, Porto Alegre, v. 12, n. 12, p. 13-30, 2010.

GIUMBELLI, Emerson. A vontade do saber: terminologias e classificações sobre 0 protestantismo brasileiro. Religião e Sociedade, Rio de Janeiro, v. 21, n. 1, p. 87119, 2000.

GIUMBELLI, Emerson. O fim da religião: dilemas da liberdade religiosa no Brasil e na França. São Paulo: Attar, 2002.

GUERRIERO, Silas. Novos movimentos religiosos: o quadro brasileiro. São Paulo: Paulinas, 2006.

HADAWAY, C. Kirk; MARLER, Penny Long. How many americans attend worship each week? An alternative approach to measurement. Journal for the Scientific Study of Religion, Storrs, v. 44, n. 3, p. 307-322, 2005.

HERVIEU-LÉGER, Danièle. O peregrino e o convertido: a religião em movimento. Petrópolis: Vozes, 2008.

IANNACCONE, Laurence. Introduction to the economics of religion. Journal of Economic Literature, Nashville, Tenn, v. 29, n. 3, p. 1465-1495, 1998.

IANNACCONE, Laurence. Never on sunny days: lessons from weekly attendance counts. Journal for the Scientific Study of Religion, Storrs, v. 43, n. 2, p. 191-207, 2004.

IANNACCONE, Laurence; FINKE, Roger; STARK, Rodney. Deregulating religion: the economics of church and state. Economic Inquiry, Long Beach, v. 35, n. 2, p. 350-364, 1997.

JUNGBLUT, Airton Luiz. 0 "mercado religioso": considerações sobre as possibilidades analíticas da teoria da "economia religiosa" para a compreensão da religiosidade contemporânea. REVER - Revista de Estudos da Religião, São Paulo, v. 12, n. 2, p. 11-22, 2012.

KING, Gary; TOMZ, Michael; WITTENBERG, Jason. Making the most of statistical analyses: improving interpretation and presentation. American Journal of Political Science, Alstin, v. 44, n. 2, p. 347-361, 2000.

LIM, Chaeyoon; PUTNAM, Robert D. Religion, social networks and life satisfaction. American Sociological Review, Aliso Viejo, v. 75, n. 6, p. 914-933, 2010.

LIMA, Diana. Alguns fiéis da Igreja Universal do Reino de Deus. Mana, Rio de Janeiro, v. 16, n. 2, p. 351-373, 2010. 
LOVEMAN, Mara; MUNIZ, Jeronimo 0.; BAILEY, Stanley R. Brazil in Black and white? Race categories, the census, and the study of inequality. Ethnic and Racial Studies, London, v. 35, n. 8, p. 1466-1483, 2012.

MACHAD0, Carly. Novos movimentos religiosos, indivíduo e comunidade: sobre família, mídia e outras mediações. Religião e Sociedade, Rio de Janeiro, v. 30, n. 2, p. 145-163, 2010.

MACHAD0, Maria das Dores Campos. Política e religião: a participação dos evangélicos nas eleições. Rio de Janeiro: FGV, 2006.

MAFRA, Clara. Os evangélicos. Rio de Janeiro: Jorge Zahar, 2001.

MARIANO, Ricardo. 0 futuro não será protestante. Ciencias Sociales y Religión/Ciências Sociais e Religião, Porto Alegre, v. 1, n. 1, p. 89-114, 1999.

MARIANO, Ricardo. Efeitos de secularização do Estado, do pluralismo e do mercado religiosos sobre as igrejas pentecostais. Civitas, Porot Alegre, v. 3, n. 1, p. 111-125, 2003.

MARIANO, Ricardo. Neopentecostais: sociologia do novo pentecostalismo no Brasil. São Paulo: Loyola, 2005.

MARIANO, Ricardo. Os neopentecostais e a teologia da prosperidade. Novos Estudos CEBRAP, São Paulo, n. 44, p. 24-44, 1996.

MESQUITA, Wania Amélia Belchior. Um pé no reino e outro no mundo: consumo e lazer entre os pentecostais. Horizontes Antropológicos, Porto Alegre, v. 13, n. 28, p. 117-144, 2007.

MONTERO, Paula. Religião, pluralismo e esfera pública no Brasil. Novos Estudos CEBRAP, São Paulo, n. 74, p. 47-65, 2006.

MONTERO, Paula; ALMEIDA, Ronaldo. 0 campo religioso brasileiro no limiar do século: problemas e perspectivas. In: RATTNER, Henrique (Ed.). Brasil no limiar do século XXI. São Paulo: EDUSP, 2000. p. 325-340.

MUNIZ, Jerônimo 0. Preto no branco? Mensuração, relevância e concordância classificatória no país da incerteza racial. Dados, Rio de Janeiro, v. 55, n. 1, p. 251-282, 2012.

NOVAES, Regina. Juventude, percepções e comportamentos: a religião faz diferença? In: ABRAMO, Helena; BRANCO, Pedro Paulo Martoni (Ed.). Retratos da juventude brasileira: análises de uma pesquisa nacional. São Paulo: Fundação Perseu Abramo 2005. p. 263-290. 
OGLAND, Curtis P.; HINOJOSA, Pedro. Religion and social attitudes: examining the contours of religion in moral judgments toward premarital sex and cohabitation in contemporary Brazil. Sociology of Religion, Washington, v. 73, n. 4, p. 411-428, 2012.

OGLAND, Curtis P.; VERONA, Ana Paula. Religion and attitudes toward abortion and abortion policy in Brazil. .Journal for the Scientific Study of Religion, Storrs, v. 50, n. 4, p. 812-821, 2011.

OLIVEIRA, Lívio Luiz Soares de; CORTES, Renan Xavier; BALBINOTTO NETO, Giácomo. A economia da religião e seus fundamentos: teste de um modelo de escolha religiosa. Estudos Econômicos, São Paulo, v. 41, n. 4, p. 811-840, 2011.

OLIVEIRA, Lívio Luiz Soares de; CORTES, Renan Xavier; BALBINOTTO NETO, Giácomo. Quem vai a Igreja? Um teste de regressão logística ordenada do modelo de Azzi-Ehrenberg para o Brasil. Estudos Econômicos, São Paulo, v. 43, n. 2, p. 335-362, 2013.

ORO, Ari Pedro; CORTEN, André; DOZON, Jean-Pierre. Igreja Universal do Reino de Deus: os novos conquistadores da fé. São Paulo: Paulinas, 2003.

PEARSON, Karl. $X$ On the criterion that a given system of deviations from the probable in the case of a correlated system of variables is such that it can be reasonably supposed to have arisen from random sampling. Philosophical Magazine Series 5, v. 50, n. 302, p. 157-175, 1900.

PEW RESEARCH CENTER. Brazil's changing religious landscape. 2013a Disponível em: http://www.pewforum.org/2013/07/18/brazils-changing-religiouslandscape $>$. Acesso em: 14 jan. 2014.

PEW RESEARCH CENTER. What surveys say about worship attendance - and why some stay home. 2013b. Disponiel em: < http://www.pewresearch.org/fact$\operatorname{tank} / 2013 / 09 / 13 /$ what-surveys-say-about-worship-attendance-and-why-some-stayhome/> . Acesso em: 14 jan. 2014.

PIERUCCI, Antônio Flávio. Bye-bye Brasil: o declínio das religiões tradicionais no Censo 2000. Estudos Avançados, São Paulo, v. 18, n. 52, p. 17-28, 2004.

PIERUCCI, Antônio Flávio. Religião como solvente: uma aula. Novos Estudos CEBRAP, São Paulo, n. 75, p. 111-127, 2006.

PIERUCCI, Antônio Flávio. De olho na modernidade religiosa. Tempo Social Revista de Sociologia da USP, São Paulo, v. 20, n. 2, p. 9-16, 2008. 
POLLAK-ELTZ, Angelina. A Igreja Universal na Venezuela. In: OR0, Ari Pedro; CORTEN, André; DOZON, Jean-Pierre. Igreja Universal do Reino de Deus: os novos conquistadores da fé. São Paulo: Paulinas, 2003. p. 79-92.

PRANDI, Reginaldo. Converter indivíduos, mudar culturas. Tempo Social- Revista de Sociologia da USP, São Paulo, v. 20, n. 2, p. 155-172, 2008.

ROLIM, Francisco Cartaxo. Pentecostais no Brasil: uma interpretação sócioreligiosa. Petrópolis: Vozes, 1985.

ROSAS, Nina. As ações sociais da Igreja Universal: recrutamento e empreendedorismo no A Gente da Comunidade de Belo Horizonte. Ciencias Sociales y Religión/Ciências Sociais e Religião, Porto Alegre, v. 14, n. 17, p. 2751, 2012.

ROSAS, Nina. Religião, mídia e produção fonográfica: o Diante do Trono e as disputas com a Igreja Universal. Religião e Sociedade, Rio de Janeiro, v. 33, n. 1, p. 167-194, 2013.

ROSAS, Nina; CASTRO, Cristina Maria de. Charismatic protestantism, gender and sexuality in Brazil. In: SHIPLEY, Heather (Ed.). Globalized religion and sexual Identity: contexts, contastations, voices. Leiden: Brill, 2014. p. 217-235.

SANCHIS, Pierre. As religiões dos brasileiros. Horizonte, Belo Horizonte, v. 1, n. 2, p. 28-43, 1997.

SCALON, Celi; GREELEY, Andrew. Projeto Religião 2002 (Banco de Dados). Rio de Janeiro: Consórcio de Informações Sociais, 2005. Disponível em: $<$ http://www.nadd.prp.usp.br/cis/ DetalheBancoDados.aspx?cod=B52>. Acesso em: 14 jan. 2014.

SMITH, Christian; DENTON, Melinda Lundquist. Soul searching: the religious and spiritual lives of American teenagers. New York: Oxford University Press, 2005.

STEENSLAND, Brian et al. The measure of American religion: toward improving the state of the art. Social Forces, Chapel Hill, v. 79, n. 1, p. 291-318, 2000.

ZEPEDA, José de Jesús Legorreta. Secularização ou ressacralização? 0 debate sociológico contemporâneo sobre a teoria da secularização. Revista Brasileira de Ciências Sociais, São Paulo, v. 25, n. 73, p. 129-141, 2010. 


\section{APÊNDICE 1}

Tabela 2 - Recodificação da religiosidade autopercebida e da frequência com que participa/ realiza atividades

\begin{tabular}{clc}
\hline Variável & \multicolumn{1}{c}{ Categorias do questionário } & Nova categorização \\
\hline \multirow{2}{*}{ Ida a } & 1. Com pouca frequência & Baixa \\
missa/culto & 3. Ulgumas vezes por ano; & Baixa \\
& 4. Duas ou três vezes por mês; & Média \\
& 5. Uma vez ou mais por semana; & Média \\
& 1. Nunca; & Alta \\
\hline 2. Menos de uma vez por ano; & Nunca \\
Fazer orações & 3. Cerca de uma ou duas vezes por ano; & Nunca \\
e/ ou & 4. Várias vezes ao ano; & Baixa \\
Participar de & 5. Cerca de uma vez por mês; & Baixa \\
atividades da & 6. Duas a três vezes por mês; & Média \\
igreja & 7. Praticamente todas as semanas; & Média \\
& 8. Todas as semanas; & Alta \\
& 9. Várias vezes por semana; & Alta \\
& 1. Extremamente religioso; & Alta \\
\hline \multirow{2}{*}{ Você se } & 2. Muito religioso; & Alta \\
descreveria & 4. Meio religioso; & Alta \\
como... & 5. Meio não religioso; & Média \\
& 6. Muito não religioso; & Média \\
& 7. Extremamente não religioso; & Média \\
\hline
\end{tabular}

Fonte: Elaboração dos autores a partir dos dados da PVRB (CIS), 2002. 


\section{APÊNDICE 2}

Tabela 3 - Frequências religiosas X filiação religiosa autodeclarada

\begin{tabular}{|c|c|c|c|c|c|}
\hline \multirow[b]{2}{*}{$\begin{array}{l}\text { Frequência que } \\
\text { participa/realiza: }\end{array}$} & \multicolumn{5}{|c|}{ Religião } \\
\hline & Católica & Pentecostal & $\begin{array}{c}\text { Não } \\
\text { pentecostal }\end{array}$ & $\begin{array}{l}\text { Sem } \\
\text { religião }\end{array}$ & Total \\
\hline \multicolumn{6}{|c|}{ Ida a culto $/ \mathrm{missa}(\mathrm{Pearson}$ chi2 $(12)=537,50 \mathrm{Pr}=0,00)$} \\
\hline Nunca & 10,71 & 2,38 & 2,17 & 66,67 & 12,54 \\
\hline Baixa & 21,52 & 4,76 & 6,52 & 15,05 & 17,80 \\
\hline Média & 39,01 & 15,08 & 15,22 & 9,68 & 32,37 \\
\hline Alta & 28,48 & 77,78 & 76,09 & 5,38 & 36,88 \\
\hline Sem resposta & 0,27 & 0,00 & 0,00 & 3,23 & 0,40 \\
\hline \multicolumn{6}{|c|}{ Atividades da igreja $($ Pearson chi2 $(12)=169,14 \operatorname{Pr}=0,00)$} \\
\hline Nunca & 57,05 & 39,29 & 30,43 & 94,62 & 55,56 \\
\hline Baixa & 14,01 & 8,33 & 21,74 & 3,23 & 12,61 \\
\hline Média & 13,19 & 14,68 & 8,70 & 0,00 & 12,47 \\
\hline Alta & 12,73 & 36,51 & 36,96 & 1,08 & 16,79 \\
\hline Sem resposta & 3,02 & 1,19 & 2,17 & 1,08 & 2,56 \\
\hline \multicolumn{6}{|c|}{ Orar/rezar (Pearson chi2 $(12)=104,57 \operatorname{Pr}=0,00)$} \\
\hline Nunca & 3,39 & 2,38 & 2,17 & 22,58 & 4,38 \\
\hline Baixa & 3,02 & 0,40 & 2,17 & 6,45 & 2,76 \\
\hline Média & 4,40 & 1,19 & 0,00 & 6,45 & 3,84 \\
\hline Alta & 88,92 & 95,63 & 95,65 & 63,44 & 88,67 \\
\hline Sem resposta & 0,27 & 0,40 & 0,00 & 1,08 & 0,34 \\
\hline \multicolumn{6}{|c|}{ Auto percepção da religiosidade (Pearson chi2 $(9)=241,68 \operatorname{Pr}=0,00$ ) } \\
\hline Baixa & 1,83 & 0,00 & 2,17 & 23,66 & 2,90 \\
\hline Média & 70,79 & 45,24 & 47,83 & 65,59 & 65,41 \\
\hline Alta & 26,74 & 54,37 & 50,00 & 10,75 & 31,15 \\
\hline Sem resposta & 0,64 & 0,40 & 0,00 & 0,00 & 0,54 \\
\hline Total (n) & 1092 & 252 & 46 & 93 & 1483 \\
\hline
\end{tabular}

Nota: 0 teste de qui-quadrado (chi2), desenvolvido por Pearson (1900), avalia a hipótese nula $\left(\mathrm{H}_{0}\right)$ de independência entre duas variáveis categóricas. 0 valor-p (Pr) representa a probabilidade da cauda direita acima do valor $\chi^{2}$ observado, para a distribuição do qui-quadrado com grau de liberdade $\mathrm{g}=$ = (1- \#linhas) (1- \#colunas) da tabela de contingência. Conclui-se pela rejeição de $\mathrm{H}_{0}$ no nível $\alpha$ se $\mathrm{p} \leq \alpha$, sendo $\alpha=0,05$ (AGRESTI; FINLAY, 2012, p. 259).

Fonte: Elaboração dos autores a partir dos dados da PVRB (CIS), 2002. 


\section{APÊNDICE 3}

Tabela 4 - Razões de chance de ser evangélico ou sem religião estimadas a partir do modelo logístico multinomial

\begin{tabular}{|c|c|c|}
\hline & Evangélicos & Sem religião \\
\hline \multicolumn{3}{|l|}{1 se alta frequência a: } \\
\hline atividades da igreja & $1.922^{* *}$ & 0.958 \\
\hline reza e oração & 1.202 & $0.309 * *$ \\
\hline \multicolumn{3}{|l|}{1 se nunca participou de: } \\
\hline cultos & 0.602 & $7.054^{* * *}$ \\
\hline atividades da igreja & 1.089 & $6.133^{* * *}$ \\
\hline reza e oração & 1.001 & 1.434 \\
\hline Região Sul & $1.712^{*}$ & 0.515 \\
\hline Região Sudeste & $1.668^{* *}$ & 1.692 \\
\hline Mãe católica & $0.117^{* * *}$ & $0.196 * * *$ \\
\hline Pai católico & $0.229 * * *$ & $0.220 * * *$ \\
\hline Constante & 0.981 & 0.332 \\
\hline $\mathrm{N}$ & 1483 & \\
\hline $\mathrm{BIC}$ & 1566.441 & \\
\hline Log-likelihood & -702.9 & \\
\hline Pseudo R2 & 0.343 & \\
\hline
\end{tabular}

Nota: Os valores apresentados na tabela representam a razão de chances (coeficientes exponenciados) de ser evangélico ou sem religião em função de determinada covariável, utilizando-se a categoria católicos como grupo de referência.

Fonte: Elaboração dos autores a partir dos dados da PVRB (CIS), 2002. 